\title{
Metode pengukuran serapan karbondioksida pada pertumbuhan anakan
}

\author{
Y. Ludang ${ }^{1 *}$, Alpian ${ }^{1}$, A. Junaedi ${ }^{1}$ \\ ${ }_{1}^{1}$ Program Studi Kehutanan, Fakultas Pertanian, Universitas Palangka Raya, Kalimantan, Indonesia
}

\begin{abstract}
Abstrak.
Pengembangan inovasi teknologi dalam pengukuran serapan $\mathrm{CO}_{2}$ tumbuhan, salah satunya dengan menggunakan metode sungkup (chamber) sampai saat ini metode tersebut belum banyak digunakan oleh para peneliti sehingga diperlukan adanya penjelasan terkait gambaran metode sungkup dalam pengukuran serapan $\mathrm{CO}_{2}$, khususnya pada pertumbuhan anakan. Tujuan dari penulisan makalah ilmiah adalah memberikan gambaran secara umum terkait prosedur pengukuran serapan $\mathrm{CO}_{2}$ pada tingkat pertumbuhan anakan dengan menggunakan metode sungkup. Metode sungkup pada awalnya digunakan untuk mengukur emisi Gas Rumah Kaca (GRK) di lahan gambut, namun seiring dengan perkembangan teknologi metode ini dapat juga digunakan untuk mengukur serapan $\mathrm{CO}_{2}$ pada tumbuhan. Ukuran sungkup yang digunakan adalah $50 \times 50 \times 30 \mathrm{~cm}$ dilengkapi dengan termometer, kipas angin dan baterai kering. Pengambilan sampel gas $\mathrm{CO}_{2}$ dalam sungkup digunakan syringe/jarum suntik berukuran $10 \mathrm{ml}$. Alat untuk menganalisis sampel gas $\mathrm{CO}_{2}$ adalah Gas Cromatography (GC). Proses pengukuran serapan $\mathrm{CO}_{2}$ dengan metode sungkup relatif cepat dan sederhana serta data yang didapatkan dapat digunakan untuk memprediksi serapan $\mathrm{CO}_{2}$ berdasarkan pertambahan umur tumbuhan. Namun demikian, keterbatasan dari metode ini adalah hanya dapat digunakan untuk mengukur serapan $\mathrm{CO}_{2}$ pada tingkat pertumbuhan anakan.
\end{abstract}

Kata kunci: metode sungkup, pengukuran serapan $\mathrm{CO}_{2}$, tumbuhan

\begin{abstract}
.
Development of technological innovation in plant $\mathrm{CO}_{2}$ absorption measurement, one of them by using method of hood (chamber), until now the method has not been widely used by the researchers so that the necessary explanations related to the description of the method of containment in measurement of $\mathrm{CO}_{2}$ uptake, especially in the growth of saplings. The purpose of this research was to provide a general overview of $\mathrm{CO}_{2}$ absorption measurement procedures at the growth rate of saplings by using hood method. The hood method was originally used to measure Greenhouse Gas (GHG) emissions in peatlands, but along with technological developments this method can also be used to measure $\mathrm{CO}_{2}$ uptake in plants. The size of the hood used is $50 \times 50 \times 30 \mathrm{~cm}$ equipped with thermometer, fan and dry battery. Sampling of $\mathrm{CO}_{2}$ gas in the hood is used syringe measuring $10 \mathrm{ml}$. While the tool for analyzing $\mathrm{CO}_{2}$ gas samples is Gas Cromatography (GC). The process of measuring $\mathrm{CO}_{2}$ uptake by hood method is relatively fast and simple and the data can be used to predict $\mathrm{CO}_{2}$ uptake based on the age of plant growth. However, the limitation of this method is only to be for $\mathrm{CO}_{2}$ uptake at the growth rate of saplings.
\end{abstract}

Keywords: chamber method, measurement of $\mathrm{CO}_{2}$ absorption, plant

\section{PENDAHULUAN}

Tumbuhan memiliki kemampuan dalam menyerap karbondioksida $\left(\mathrm{CO}_{2}\right)$ dari udara melalui proses fotosintesis. Fotosintesis merupakan proses perubahan senyawa anorganik $\left(\mathrm{CO}_{2}\right.$ dan $\left.\mathrm{H}_{2} \mathrm{O}\right)$ pada tumbuhan menjadi senyawa organik (karbohidrat) dan $\mathrm{O}_{2}$ (oksigen) dengan bantuan cahaya matahari (Ai \& Banyo 2011). Aktifitas proses fotosintesis pada tumbuhan dapat diamati secara eksponensial seperti jumlah bahan baku yang digunakan atau dilepaskan maupun berbagai reaksi yang terjadi didalamnya dan tidak terkecuali adalah jumlah $\mathrm{CO}_{2}$ yang diserap oleh tumbuhan.

\footnotetext{
${ }^{*}$ Korespondensi Penulis

Email : yetrie@pplh.upr.ac.id
} 
Berbagai metode pengukuran serapan $\mathrm{CO}_{2}$ oleh tumbuhan sudah sangat berkembang saat ini, baik itu metode pengukuran secara langsung maupun metode secara tidak langsung. Metode pengukuran $\mathrm{CO}_{2}$ secara langsung adalah dengan cara melakukan perusakan terhadap bagian tumbuhan (akar, batang, daun) yang akan diteliti, seperti pengukuran serapan $\mathrm{CO}_{2}$ tumbuhan dengan metode karbohidrat. Purwaningsih (2007) dalam Sukmawati et al. (2015), pengukuran serapan karbondioksida dapat diukur dengan metode karbohidrat, karena dalam proses fotosintesis jumlah massa karbondioksida berbanding lurus dengan jumlah karbon dalam karbohidrat. Metode pengukuran serapan $\mathrm{CO}_{2}$ secara tidak langsung adalah dengan menggunakan alat pengukur tanpa merusak dari tumbuhan itu sendiri. Contoh metode tersebut adalah dengan menggunakan sungkup (chamber) ukuran $50 \times 50 \times 30 \mathrm{~cm}$ yang dilengkapi baterai kering, termometer dan kipas angin kecil. Analisis sampel gas $\mathrm{CO}_{2}$ menggunakan alat Gas Cromatography (GC). Metode pengukuran dengan sungkup ini hanya dapat digunakan untuk mengukur serapan $\mathrm{CO}_{2}$ pada tingkat anakan tumbuhan dan penggunaan metode ini di kalangan peneliti masih sangat terbatas.

Sehubungan dengan itu, untuk lebih memperkenalkan penggunaan metode pengukuran serapan $\mathrm{CO}_{2}$ dengan sungkup ini diperlukan penjelasan gambaran secara umum terkait tahapan prosedur yang harus dilakukan. Tujuan dari penulisan makalah ini adalah memberikan gambaran secara umum terkait prosedur pengukuran serapan $\mathrm{CO}_{2}$ pada tingkat pertumbuhan anakan dengan menggunakan metode sungkup (chamber).

\section{METODOLOGI}

Metode yang digunakan dalam penyusunan makalah ini adalah melalui studi literatur dari berbagai jurnal nasional, jurnal internasional atau laporan hasil penelitian yang terkait dengan penggunaan metode sungkup (chamber) dalam pengukuran serapan $\mathrm{CO}_{2}$ pada tingkat pertumbuhan anakan.

\section{HASIL DAN PEMBAHASAN}

\subsection{Penggunaan metode sungkup (chamber) dalam pengukuran serapan karbondioksida}

Metode sungkup pada awalnya digunakan untuk mengukur emisi Gas Rumah Kaca (GRK) di lahan gambut. Kementerian Pertanian (2011), beberapa ukuran sungkup yang digunakan untuk pengambilan sampel GRK di lahan gambut terdiri dari 3 ukuran, yaitu :

1. Sungkup ukuran $50 \times 50 \times 30 \mathrm{~cm}$, digunakan untuk mengukur fluks GRK untuk tanaman perkebunan. 
2. Sungkup ukuran $50 \times 15 \times 30 \mathrm{~cm}$, digunakan untuk mengukur fluks GRK untuk tanaman pangan (sela).

3. Sungkup ukuran $50 \times 50 \times 100 \mathrm{~cm}$, digunakan untuk mengukur fluks GRK untuk tanaman dengan sistem surjan (padi sawah dan gogo).

Seiring dengan perkembangan ilmu pengetahuan dan teknologi, penggunaan metode tersebut kemudian berkembang tidak hanya terbatas dalam pengukuran emisi GRK, namun dapat juga digunakan untuk mengukur serapan $\mathrm{CO}_{2}$ pada pertumbuhan tingkat anakan. Ukuran sungkup yang digunakan dalam pengukuran serapan $\mathrm{CO}_{2}$ pada pertumbuhan anakan adalah $50 \times 50 \times 30 \mathrm{~cm}$. Metode tersebut pertama kali digunakan oleh Ludang (2013), pada penelitian dengan judul "Keragaman Hayati Ruang Terbuka Hijau Berbasis Pengetahuan Ulayat di Kota Palangka Raya". Ludang dan Junaedi (2015), menerapkan pengukuran serapan $\mathrm{CO}_{2}$ pada anakan tumbuhan buah-buahan dengan judul "The Role of Plant Tillers toward Carbon Dioxide Sequestration". Selanjutnya Ludang (2015), menggunakan metode tersebut untuk mengukur serapan $\mathrm{CO}_{2}$ pada tumbuhan ulayat dengan judul "Serapan Karbon Dioksdia Tumbuhan Ulayat untuk Ruang Terbuka Hijau di Kota Palangka Raya".

\subsection{Pengukuran Serapan Karbondioksida pada Pertumbuhan Anakan dengan Metode Sungkup (chamber)}

\subsubsection{Peralatan yang digunakan}

Ukuran sungkup dalam pengukuran serapan karbondioksida $\left(\mathrm{CO}_{2}\right)$ pada pertumbuhan anakan 50 x 50 x $30 \mathrm{~cm}$. Sungkup dilengkapi dengan beberapa peralatan pendukung diantaranya :

1. Sungkup berbentuk empat persegi panjang berukuran $50 \times 50 \times 30 \mathrm{~cm}$ untuk pengambilan sampel gas $\mathrm{CO}_{2}$. Sungkup dilengkapi dengan septum, lubang termometer, kipas angin kecil, baterai kering serta ukuran ketinggian pasir untuk menutupi keliling sungkup.

2. Termometer terdiri dari: termometer yang ditempatkan di dalam sungkup dan termometer yang ditempatkan di luar sungkup. Fungsi termometer di dalam sungkup adalah untuk mengukur perubahan suhu pada setiap interval pengambilan sampel gas, sedangkan termometer yang di luar sungkup digunakan untuk mengukur suhu luar di sekitar lokasi penelitian pada setiap interval pengambilan sampel gas $\mathrm{CO}_{2}$.

3. Syringe (jarum suntik ukuran $10 \mathrm{ml}$ ), fungsinya adalah untuk mengambil sampel gas $\mathrm{CO}_{2}$ di dalam sungkup pada setiap interval pengkuran.

4. Karet penutup syringe, berfungsi untuk menutup ujung syringe/jarum suntik agar supaya sampel gas $\mathrm{CO}_{2}$ yang sudah diambil tidak keluar. 
5. Kipas angin, digunakan untuk meratakan udara/sampel gas $\mathrm{CO}_{2}$ yang ada di dalam sungkup.

6. Baterai kering, digunakan untuk menggerakkan kipas angin di dalam sungkup.

7. Stop watch, digunakan sebagai penanda interval waktu pada saat awal pengambilan sampel gas $\mathrm{CO}_{2}$ di dalam sungkup.

3.2.2. Prosedur Pengukuran Serapan $\mathrm{CO}_{2}$ pada Pertumbuhan Anakan dengan Sungkup (Chamber)

Anakan tumbuhan yang akan diukur kemampuan serapan $\mathrm{CO}_{2}$ idealnya memiliki ketinggian maksimal $30 \mathrm{~cm}$. Hal ini untuk memudahkan ketika anakan tumbuhan tersebut dimasukkan ke dalam sungkup agar tidak mengalami kerusakan/patah. Adapun prosedur pengukuran serapan $\mathrm{CO}_{2}$ pada pertumbuhan anakan sebagai berikut:

1. Pastikan anakan tumbuhan yang di ukur dalam keadaan sehat dan tidak mengalami stres.

2. Anakan tumbuhan tersebut kemudian ditutup dengan sungkup dan di setiap sisinya ditutupi dengan pasir agar gas $\mathrm{CO}_{2}$ dalam sungkup tidak keluar.

3. Pasang termometer untuk pengukuran suhu di dalam sungkup dan termometer untuk pengukuran suhu luar di sekitar lokasi penelitian.

4. Hidupkan kipas angin yang ada di dalam sungkup dan penutup karet/septum di atas sungkup dibuka 2-3 menit agar konsentrasi udara dalam sungkup merata serta stabil, kemudian ditutup kembali.

5. Mempersiapkan syringe/jarum suntik untuk pengambilan sampel gas $\mathrm{CO}_{2}$ dengan cara membuka tutup karet pada ujung syringe.

6. Proses pengambilan sampel gas $\mathrm{CO}_{2}$ di dalam sungkup dapat dilakukan sesuai dengan periode waktu dan interval pengambilan gas $\mathrm{CO}_{2}$.

7. Catat suhu di dalam sungkup dan suhu luar di sekitar lokasi penelitian sesuai dengan periode waktu dan interval pengambilan sampel gas $\mathrm{CO}_{2}$.

8. Setelah proses pengambilan gas $\mathrm{CO}_{2}$ selesai, sungkup yang menutupi anakan tumbuhan di buka kembali.

9. Sampel gas $\mathrm{CO}_{2}$ kemudian di analisis dengan alat Gas Cromatography untuk mendapat data konsentrasi $\mathrm{CO}_{2}$ pada masing-masing periode dan interval waktu pengambilan gas $\mathrm{CO}_{2}$.

10. Data hasil analisis sampel gas $\mathrm{CO}_{2}$ tersebut kemudian dilakukan pengolahan data untuk mendapatkan data serapan dan fluktuasi $\mathrm{CO}_{2}$ oleh anakan tumbuhan setiap periode waktu dan interval pengambilan gas $\mathrm{CO}_{2}$. 
11. Proses pengambilan sampel gas $\mathrm{CO}_{2}$ tersebut dapat dilaksanakan secara berulang sesuai dengan periode waktu dan interval yang telah ditentukan.

12. Jika proses pengambilan sampel gas $\mathrm{CO}_{2}$ sudah selesai dilaksanakan, sebaiknya dilakukan analisis biomassa, persen dan kandungan karbon setiap anakan tumbuhan dengan metode gravimetri untuk mendapatkan data pendukung.

Sungkup yang digunakan dalam proses pengukuran serapan $\mathrm{CO}_{2}$ pada pertumbuhan anakan, seperti pada Gambar 1.

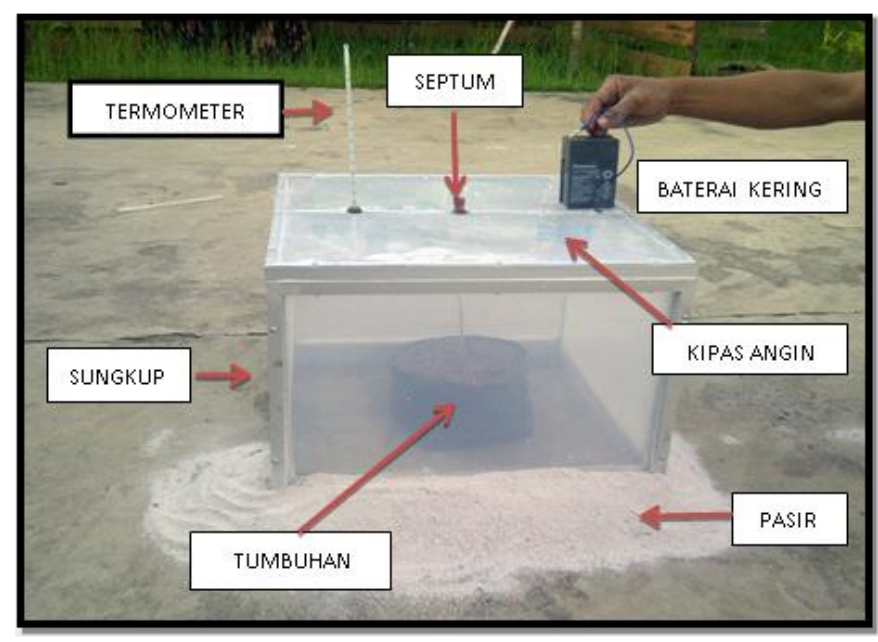

Gambar 1. Pengukuran serapan $\mathrm{CO}_{2}$ anakan tumbuhan dengan metode sungkup (Chamber).

Pengukuran serapan $\mathrm{CO}_{2}$ pada anakan tumbuhan dengan metode sungkup, memiliki beberapa kelebihan, yaitu prosesnya relatif sederhana dan cepat serta data serapan $\mathrm{CO}_{2}$ pada anakan tumbuhan tersebut dapat digunakan untuk memprediksi jumlah $\mathrm{CO}_{2}$ yang mampu diserap seiring dengan pertambahan umur tumbuhan. Kelemahan dari metode ini adalah ketinggian anakan tumbuhan maksimal 30-40 cm, sampel gas $\mathrm{CO}_{2}$ yang sudah diambil dengan syringe harus segera dianalisis sebelum gas $\mathrm{CO}_{2}$ tersebut kadaluarsa (maksimal 3 hari dari mulai proses pengambilan gas $\mathrm{CO}_{2}$ ).

\section{KESIMPULAN DAN SARAN}

Pengukuran serapan $\mathrm{CO}_{2}$ pada pertumbuhan anakan dengan metode sungkup (chamber) merupakan pengembangan inovasi teknologi dalam mengukur jumlah $\mathrm{CO}_{2}$ yang diserap tumbuhan. Proses pengukuran yang relatif cepat, sederhana dan data yang dihasilkan dapat digunakan untuk memprediksi 
serapan $\mathrm{CO}_{2}$ berdasarkan pertambahan umur tumbuhan. Namun demikian metode ini hanya dapat digunakan untuk mengukur serapan $\mathrm{CO}_{2}$ pada tingkat peertumbuhan anakan dengan ketinggian maksimal 30-40 cm dari permukaan tanah.

Peneliti yang tertarik untuk menggunakan metode sungkup (chamber) dalam pengukuran serapan $\mathrm{CO}_{2}$ anakan tanaman, sebaiknya memerlukan kerjasama dengan Laboratorium Balai Penelitian Lingkungan Pertanian Jakenan, Pati, Jawa Tengah.

\section{Ucapan Terima Kasih}

Ucapan terima kasih kami sampaikan kepada (1) Kementerian Riset, Teknologi dan Pendidikan Tinggi (2) Rektor Universitas Palangka Raya (3) Lembaga Penelitian dan Pengabdian Kepada Masyarakat atas dukungannya terhadap penelitian ini yang dibiayai dana BOPTN tahun anggaran 2017.

\section{Daftar Pustaka}

Ai NS dan Banyo Y. 2011. Konsentrasi klorofil daun sebagai indikator kekurangan air pada tanaman. Jurnal Ilmiah Sains 11(2):166-173.

Kementerian Pertanian. 2011. Panduan Teknis Pengukuran emisi gas rumah kaca. Penelitian dan pengembangan teknologi pengelolaan lahan gambut berkelanjutan untuk meningkatkan sekuestrasi karbon dan mitigasi gas rumah kaca. Badan penelitian dan pengembangan pertanian. Indonesia climate change trust fund (ICCTF-Kementan).

Ludang Y. 2013. Keragaman hayati ruang terbuka hijau berbasis pengetahuan ulayat di Kota Palangka Raya [Disertasi]. Program Doktor Bidang Keahlian Teknik Lingkungan. Jurusan Teknik Lingkungan. Fakultas Teknik Sipil dan Perencanaan. Institut Teknologi Sepuluh Nopember. Surabaya.

Ludang Y and Junaedi A. 2015. The role of plant tillers toward carbon dioxide sequestration. Journal of Agriculture and Food Technology 5(2):15-20.

Ludang Y. 2015. Serapan karbon dioksida tumbuhan ulayat untuk ruang terbuka hijau di kota Palangka Raya. Jurnal Purifikasi 15(2):114-120.

Sukmawati T, Fitrihidajati H dan Indah KN. 2015. Penyerapan karbon dioksida pada tanaman hutan kota di Surabaya. Jurnal Lentera Bio 4(1):108-111. 